\title{
Electrospun silver ion-loaded calcium phosphate/ chitosan antibacterial composite fibrous membranes for guided bone regeneration
}

This article was published in the following Dove Press journal: International Journal of Nanomedicine

\author{
Shue Jin' \\ Jidong $\mathrm{Li}^{\prime}$ \\ Jian Wang' \\ Jiaxing Jiang' \\ Yi Zuo' \\ Yubao $\mathrm{Li}^{1}$ \\ Fang Yang ${ }^{2}$ \\ 'Research Center for Nano- \\ Biomaterials, Analytical and Testing \\ Center, Sichuan University, Chengdu \\ 610064, China; ${ }^{2}$ Department of \\ Biomaterials, Radboud University \\ Medical Center, Nijmegen, \\ the Netherlands
}

\begin{abstract}
Purpose: The purpose of this study is to construct a guided bone regeneration membrane that is similar to bone components and structurally resembles the native extracellular matrix with sufficient antibacterial properties.
\end{abstract}

Materials and methods: A novel type of biomimetic and bioactive silver ion-loaded calcium phosphate/chitosan (Ag-CaP/CS) membrane with antibacterial ability was successfully developed by incorporation of silver ion-loaded $\mathrm{CaP}$ via a one-step electrospinning method and subsequently crosslinked with vanillin.

Results: Evaluation of the physicochemical properties revealed that the fabricated fibrous membranes mimicked the extracellular matrix structure and the addition of $\mathrm{CaP}$ significantly increased the mineralization ability of the membranes. Importantly, the Ag-CaP/CS membranes exhibited a sustainable release of $\mathrm{Ag}^{+}$, which in turn inhibited the adhesion and growth of Staphylococcus mutans. The results of cell adhesion and MTT assay revealed that the Ag-CaP/CS membranes were cytocompatible with bone marrow stromal cells.

Conclusion: The fabricated electrospinning $\mathrm{Ag}-\mathrm{CaP} / \mathrm{CS}$ nanofiber membranes with excellent biocompatibility and strong antimicrobial properties have great potential to be used for guided bone regeneration.

Keywords: antimicrobial, electrospinning, chitosan, membrane, guided bone regeneration

\section{Introduction}

Insufficient alveolar bone volume is a common clinical problem that has a direct impact on the survival rate of dental implant treatment. Guided bone regeneration (GBR) is a procedure aiming for the reconstruction of impaired bone tissue, and has become increasingly popular in oral and maxillofacial surgery for augmentation of alveolar bone. ${ }^{1-4}$ This technique makes use of a membrane barrier to direct the growth of neo-bone tissue while preventing the ingrowth of fibrous tissues to the bone defects. ${ }^{5-7}$ In the past decades, a variety of barrier membranes, including non-absorbable, for example, polytetrafluoroethylene, and absorbable membranes, such as polyglycolic acid, poly (lactic acid), and collagen membranes, have been developed and applied for GBR techniques. ${ }^{8-10}$ Although the commercially available GBR membranes showed certain positive outcomes, they are at risk of a biomaterial-centered infection, especially when the membranes are exposed to infected tissue or an area with high accessibility of bacteria, such as the oral cavity. Hence, development of GBR membranes with sufficient antibacterial ability may be a solution for this problem.

In addition to sufficient antibacterial ability, some other essential properties of GBR membranes are required, such as excellent biocompatibility, cell immobility, 
tissue integration, mechanical stability, optimal porosity, and clinical manageability, ${ }^{11}$ which may directly influence the outcome of the GBR approach. It is well accepted that a biomaterial mimicking the extracellular matrix (ECM) in terms of both the structure and the components is in favors of cell functionality and accelerates the process of injured tissue regeneration. ${ }^{12}$ Recently, how to successfully develop a GBR membrane resembling native bone ECM both in composition and structure has become a hot research issue. To manufacture micro-nanoscaled fibers that mimic the structure and morphology of primordial ECM for bone tissue regeneration, electrospinning has been widely used as a proven technique. During electrospinning, polymer solutions are sprayed and spun in a strong electric field and eventually solidified into nanofibers. Some biocompatible and biodegradable polymers are broadly used for electrospinning, including poly (lactic acid), poly (vinyl alcohol), poly (lactic-co-glycolic acid), and poly (epsilon-caprolactone). In addition, electrospinning is a rapid, straightforward, and low-cost method to produce nanofiber-based membranes with high porosity and good pore size distribution. ${ }^{13,14}$ An optimal porous structure of the GBR membrane is essential for the growth of cells and the exchange of nutrients. ${ }^{4}$ Therefore, electrospinning was employed to fabricate fibrous membrane for GBR applications. ${ }^{15,16}$

From a materials point of view, natural human bone is a complex of organic-inorganic composite consisting of calcium phosphate $(\mathrm{CaP})$ nanoparticles and collagen nanofibers. However, electrospinning of collagen denatures collagen to gelatin, and the solvent used in electrospinning will weaken the typical biological properties of collagen and cannot imitate the component of ECM. ${ }^{17}$ Consequently, other types of natural polymers have been considered, including chitosan (CS). CS is obtained by deacetylation of chitin, which is the second most abundant polysaccharide in the world. ${ }^{18,19} \mathrm{CS}$ has attracted great research interest in the biomedical field because of its excellent performance of biocompatibility, blood compatibility, biosecurity, and microbial degradability. ${ }^{20-23}$ Silver ions $\left(\mathrm{Ag}^{+}\right)$as antibacterial agents have broad-spectrum antibacterial properties, and their resistance to bacteria has rarely been reported relative to traditional antibiotics. ${ }^{24-26}$ Therefore, $\mathrm{Ag}^{+}$and silver nanoparticles have been extensively studied in the medical field. ${ }^{27,28}$ The antimicrobial activity of silver is mainly dependent on the silver cation $\left(\mathrm{Ag}^{+}\right)$, which can bind strongly to some electron donor groups in biological molecules. In addition, these silver agents are often incorporated in carriers to achieve a sustained release of $\mathrm{Ag}^{+} \cdot{ }^{29} \mathrm{CaP}$ materials, such as nano-hydroxyapatite, have been found to provide a large reservoir of silver ions, which could be released gradually resulting in long-term antimicrobial activity. Our previous studies have proved that the silver ion-loaded CaP system possesses strong antibacterial activity, good biocompatibility, as well as causes slow release of silver ions. ${ }^{30,31}$ Moreover, chemical composition of $\mathrm{CaP}$ is similar to that of natural bone and it has the necessary elements for human metabolism. Importantly, its chemically reactive groups can form chemical bonds with the bone tissue. ${ }^{32}$ Our goal is to design and fabricate a biomimetic and bioactive silver ionloaded $\mathrm{CaP} / \mathrm{CS}$ (Ag-CaP/CS) membrane with antibacterial ability, via electrospinning, which resembles the ECM so as to create conducive living milieu to induce cells to function naturally. It was hypothesized that the Ag-CaP/CS fibrous composite GBR membrane with optimal silver ion content could controllably release silver ions from the fibers to achieve the desired cytocompatibility and sufficient antibacterial effect simultaneously, thus overcoming the drawback of a biomaterial-centered infection with use of the current commercially available GBR membranes. To this end, Ag-CaP/CS fibrous membranes were firstly prepared by electrospinning, and the physicochemical properties, biocompatibility, as well as the antimicrobial activity of the membranes were then studied by in vitro tests in comparison with pure $\mathrm{CS}$ and $\mathrm{CaP} / \mathrm{CS}$ fibrous membrane without silver as the control groups. In general, the higher the content of $\mathrm{CaP}$, the better the osteoconductivity of composite bone repair materials. However, our preliminary experiments showed CaP content higher than $20 \mathrm{wt} \%$ made electrospinning of composite membrane difficult. Thus, $20 \mathrm{wt} \%$ of $\mathrm{CaP}$ was utilized in the present study. In order to determine the optimal concentration of silver ions, we fabricated two types of membranes with different silver content and evaluated the antibacterial activity and cytocompatibility to determine which silver ion concentrations in the composite membrane can show strong antibacterial activity and good cytocompatibility simultaneously.

\section{Materials and methods Materials}

Medical grade CS (degree of deacetylation: 85\%; molecular weight: 200-400 kDa) was bought from Heppe Medical Chitosan GmbH (Halle, Germany). Trifluoroacetic acid (TFA) and vanillin were purchased from Sigma-Aldrich Co., Ltd (Gillingham, UK). CaP and silver ion-loaded $\mathrm{CaP}$ (Ag-CaP) were prepared using a wet synthesis method as described previously. ${ }^{31}$

\section{Membrane preparation}

CS was dissolved in TFA to form a $5 \mathrm{wt} \% \mathrm{CS}$ solution at $40^{\circ} \mathrm{C}$. Then $\mathrm{Ag}-\mathrm{CaP}$ or $\mathrm{CaP}$ was added and mixed by 
ultrasonic mixing for 30 minutes. Electrospinning was performed and the spinneret needle was maintained at a voltage of $26 \mathrm{kV}$ by a high voltage power, and an aluminum foil under the needle at a distance of $20 \mathrm{~cm}$ was used as the collector. The pump rate was set at $1.0 \mathrm{~mL} / \mathrm{h}$. A total of four types of membranes were prepared in this study as shown in Table 1, including pure $\mathrm{CS}, \mathrm{CaP} / \mathrm{CS}$ without silver and $\mathrm{CaP} / \mathrm{CS}$ with different silver content. A scanning electron microscope (SEM, JSM-6510LV; JEOL, Tokyo, Japan) was used to characterize the structure of the fabricated materials. Energy dispersive spectroscopy (EDS, X-Max ${ }^{\mathrm{N}} 20$; Oxford, UK) was carried out to observe the distribution of the fillers in the fiber matrix. One hundred fibers per sample were used to measure the diameter by Image-Pro Plus.

\section{Crosslinking}

Before crosslinking, the membranes were stabilized according to the literature. ${ }^{33}$ In brief, the membranes were first stabilized by soaking them for 20 minutes in $0.5 \%$ sodium hydroxide $(\mathrm{NaOH})$ dissolved in $100 \%$ ethanol, followed by five times washing in PBS for 30 seconds. The stabilized membranes were then crosslinked in $5 \%(\mathrm{w} / \mathrm{v})$ vanillin dissolved in ethanol for 2 hours at $50^{\circ} \mathrm{C}$. Subsequently, the crosslinked membranes were rinsed with $100 \%$ ethanol for 5 minutes and then with PBS for 30 seconds to remove the unreacted vanillin.

\section{Simulated body fluid (SBF) immersion test} Immersion studies were performed by incubating a membrane (disk shape with a diameter of $15 \mathrm{~mm}$ ) in $10 \mathrm{~mL} \mathrm{SBF}$ solution in a $15 \mathrm{~mL}$ tube. The $\mathrm{pH}$ value of the SBF solution was adjusted to 7.4 before membrane immersion. ${ }^{34}$ Three samples were used for each condition. All the tubes were placed in a water bath at $37^{\circ} \mathrm{C}$ under continuous shaking. After immersion periods of 1 and 2 weeks, the membranes were gently washed with deionized water and freeze-dried. The membranes were then examined by X-ray powder diffraction (XRD, DX-2500; Dandong Fangyuan Instrument Co., Ltd., Dandong, China) and observed by SEM after sputter coating with gold.

\section{In vitro $\mathrm{Ag}^{+}$release}

The fibrous membranes with $\mathrm{Ag}^{+}$(A1 and A2) were cut into square pieces with a length of $10 \mathrm{~mm}$ and then immersed in

Table I The compositions of the fabricated samples

\begin{tabular}{lllll}
\hline Sample & CS & A0 & Al & A2 \\
\hline The ratio of CS to calcium phosphate & Pure CS & $4: 1$ & $4: 1$ & $4: 1$ \\
Silver content & 0 & 0 & $0.075 \%$ & $0.144 \%$ \\
\hline
\end{tabular}

Abbreviation: CS, chitosan.

International Journal of Nanomedicine 2018:13
$3 \mathrm{~mL}$ PBS. All samples were incubated at room temperature and placed on oscillators at $90 \mathrm{rpm}$. The supernatant was collected at predetermined time points. After digestion by $\mathrm{HNO}_{3}$ and dilution at a suitable ratio for testing, the Ag concentration of the solution was tested by atomic absorption spectroscopy (SpectrAA 220Z; Varian, Melbourne, VIC, Australia). Meanwhile, A0 membrane was also cut into square pieces with a length of $10 \mathrm{~mm}$ and $\mathrm{Ag}^{+}$was physically absorbed on $\mathrm{A} 0$ by immersion of the membrane in $\mathrm{AgNO}_{3}$ aqueous solution for 2 hours, then the $\mathrm{Ag}^{+}$physically absorbed $\mathrm{A} 0$ membrane was dried in a vacuum oven, in which the designed $\mathrm{Ag}^{+}$content is the same as that in $\mathrm{A} 2$ membrane. Thereafter, the release of $\mathrm{Ag}^{+}$from the $\mathrm{Ag}^{+}$physically absorbed $\mathrm{A} 0$ membrane for 1 day, immersion in PBS was also tested by using the abovementioned methods.

\section{Antimicrobial properties assessment}

\section{Antibacterial adhesion assay}

The membranes were cut to a size of $5 \times 5 \mathrm{~mm}$ and sterilized by ethylene oxide gas prior to the test. Streptococcus mutans (ATCC 25175) in brain-heart infusion (BHI) broth (Oxoid Ltd, Basingstoke, UK) or Porphyromonas gingivalis (ATCC 33277) in tryptic soy broth (Sigma-Aldrich Co., St Louis, MO, USA) were adjusted to a density of $10^{6}$ colony forming units $/ \mathrm{mL}$. Then, each membrane was immersed in $2 \mathrm{~mL}$ bacterial suspension at $37^{\circ} \mathrm{C}$. After 24 hours, the membranes were gently washed with sterilized PBS to remove the unattached bacterial cells. After being fixed with $2.5 \%(\mathrm{v} / \mathrm{v})$ glutaraldehyde (Sigma-Aldrich, St Louis, MO, USA) for 2 hours, the samples were dehydrated with a series of ethanol solutions $(30 \%, 50 \%, 70 \%, 80 \%, 90 \%, 95 \%$, and $100 \%$ for 10 minutes each) and dried using the critical point method. At the end of this procedure, the samples were coated with gold and viewed via SEM.

\section{Direct contact test (DCT)}

DCT, based on the turbidimetric determination of bacterial growth in 96-well microtiter plates, was used to evaluate the antibacterial activity of root canal sealing materials. ${ }^{35,36}$ In this study, a modified DCT method was adopted to evaluate the antibacterial ability of the fibrous membranes. In brief, the test membranes $(5 \times 5 \mathrm{~mm}, \mathrm{n}=4)$ were placed separately in 24-well microtiter plates (named as group A well plates). Twenty microliters of bacterial suspension $\left(\sim 1 \times 10^{6}\right.$ colony forming units $/ \mathrm{mL}$ ) was added to the membranes and incubated at $37^{\circ} \mathrm{C}$ for 1 hour to facilitate direct contact of bacteria with the membranes. BHI broth $(460 \mu \mathrm{L})$ was then added to each well and the plates were gently vortex mixed for 2 minutes; $30 \mu \mathrm{L}$ of the supernatant was then transferred to 
another well containing fresh BHI broth medium $(400 \mu \mathrm{L})$ and again mixed for 2 minutes (named as group B well plates). Both groups A (in the presence of the membranes) and $\mathrm{B}$ (with the membranes not present) well plates were further incubated at $37^{\circ} \mathrm{C}$ anaerobically for up to 24 hours. At each predetermined time point, $200 \mu \mathrm{L}$ of liquid was transferred from each well to a sterilized 96-well microtiter plate and the bacterial growth was measured at $650 \mathrm{~nm}$ and $37^{\circ} \mathrm{C}$ using a microplate spectrophotometer (PerkinElmer 1420 Multilabel Counter; PerkinElmer, Inc., Waltham, MA, USA). After that, the liquid was transferred back to the original wells and the incubation was continued. Empty wells without test materials $(n=4)$ served as controls. All the experiments were carried out under aseptic conditions.

\section{Cytocompatibility}

\section{Cell culture}

Cell attachment, spread, and proliferation on the different membranes were evaluated using bone marrow stromal cells (BMSCs). Two young Sprague Dawley rats (2 months old and weight about $100 \mathrm{~g}$ ) obtained from the experimental animal center of Sichuan University were employed for extraction of BMSCs, which was approved by the Ethics Committee of Sichuan University, and all operation procedures and animal care were performed in compliance with the Guide for the Care and Use of Laboratory Animals. BMSCs were obtained from the tibiae and femora of young Sprague Dawley rats and cultured in $\alpha$-Minimum Essential Medium supplemented with $20 \%$ fetal bovine serum, $100 \mathrm{U} / \mathrm{mL}$ penicillin, $100 \mathrm{mg} / \mathrm{mL}$ streptomycin, $0.219 \mathrm{mg} / \mathrm{mL}$ L-glutamine, and $100 \mathrm{mM}$ HEPES buffer (Thermo Fisher Scientific, Waltham, MA, USA) in a humidified incubator with $5 \% \mathrm{CO}_{2}$ at $37^{\circ} \mathrm{C}$. The culture medium was changed every other day. The third passage of BMSCs was used in the experiments. Prior to seeding, all the membranes of $\sim 1 \mathrm{~mm}$ thickness were cut into discs of $10 \mathrm{~mm}$ in diameter, sterilized by ethylene oxide gas, and pre-wetted in the culture medium for 24 hours. BMSCs were seeded onto the pre-wetted membranes $\left(2 \times 10^{4}\right.$ cells per membrane). The seeded membranes were then cultured in a humidified incubator $\left(37^{\circ} \mathrm{C}\right.$, $5 \% \mathrm{CO}_{2}$ ) for 11 days with the medium changed every 2 days. Cells cultured without materials were assigned as control.

\section{Attachment and proliferation of the BMSCs}

After 4 and 7 days, the samples were collected for SEM observation. The cell membrane constructs were rinsed in PBS, fixed with 3\% glutaraldehyde, and dehydrated in graded ethanol concentrations $(25 \%, 50 \%, 75 \%, 90 \%, 95 \%$, and $100 \% \mathrm{v} / \mathrm{v}$ in distilled $\mathrm{H}_{2} \mathrm{O}$ ). After that, the samples were rinsed with isoamyl acetate and then dried in supercritical $\mathrm{CO}_{2}$. Thereafter, the samples were sputter coated with $\mathrm{Au}$ and observed by SEM.

The proliferation of BMSC cells cultured on all the membranes was determined by MTT assay (Amresco, Cleveland, $\mathrm{OH}, \mathrm{USA}$ ) according to the instruction of the manufacturer. The absorbance at $490 \mathrm{~nm}$ was measured with a microplate reader (PerkinElmer 1420 Multilabel Counter, PerkinElmer, Inc.) after $1,4,7$, and 11 day (s) of incubation $(\mathrm{n}=3)$.

\section{Statistical analysis}

For quantitative analysis, Student's $t$-tests were used to assess differences between two groups and multiple comparisons were performed via one-way analysis of variance test using SPSS (v. 11.0). $P$-values $<0.05$ were considered statistically significant. Data are expressed as mean values \pm SD.

\section{Results and discussion Morphology of fibrous membranes}

Fibrous membranes were prepared from all the solutions by the same parameters via electrospinning. All the membranes were constructed with fibers with a broad diameter range and they presented a randomly oriented arrangement (Figure 1). For those groups with $\mathrm{CaP}$, the surface of fibers was rougher than that of pure CS fibers due to the exposure of $\mathrm{CaP}$ particles. A porous structure was formed by the randomly arranged fibers, which would facilitate the exchange of nutrients and waste of cell metabolism.

\section{XRD and Fourier-transform infrared analysis}

XRD patterns of hydroxyapatite (HA) and silver-loaded hydroxyapatite (HA-Ag), electrospun membranes (CS, $\mathrm{A} 0$ and A1), and A1 immersed in SBF for 2 weeks (A1-SBF) are presented in Figure 2A. The characteristic diffraction peaks of HA-Ag were almost the same as those of HA, indicating that the addition of $\mathrm{Ag}^{+}$had little effect on the crystal structure of HA. However, the characteristic diffraction peaks of HA were not observed in A0 and A1 samples. Instead, the characteristic diffraction peaks of $\mathrm{CaHPO}_{4}$ were confirmed, indicating the apatitic $\mathrm{CaP}$ was dissolved and transformed into $\mathrm{CaHPO}_{4}$ in the acidic solution of TFA during the electrospinning process. HA will dissolve and transform into $\mathrm{CaHPO}_{4}$ in acidic solutions of $\mathrm{pH}$ value $<4.5 .{ }^{37}$ Since TFA with low $\mathrm{pH}$ value was used as the solvent in this experiment, the electrospinning fibers eventually contain $\mathrm{CaHPO}_{4}$ rather than HA. 


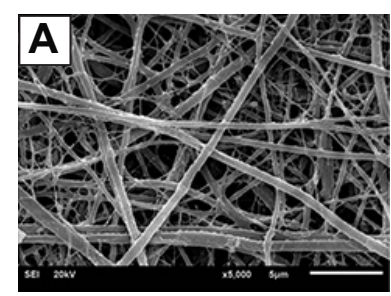

E

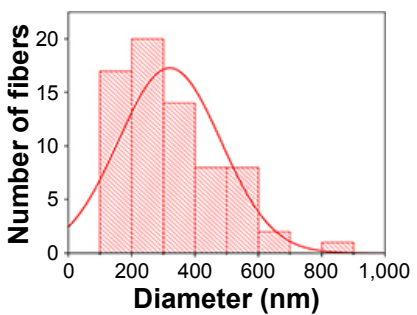

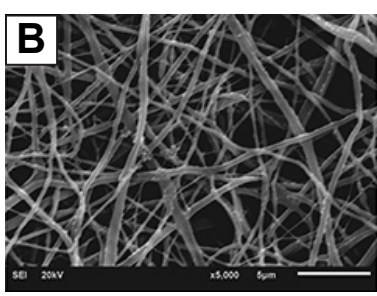

$\mathbf{F}$

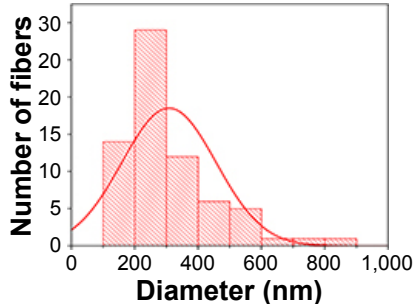

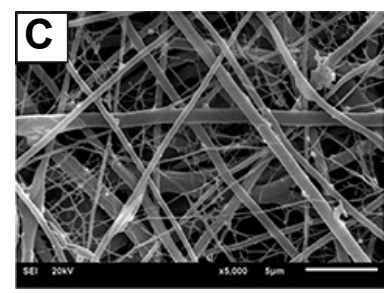

G

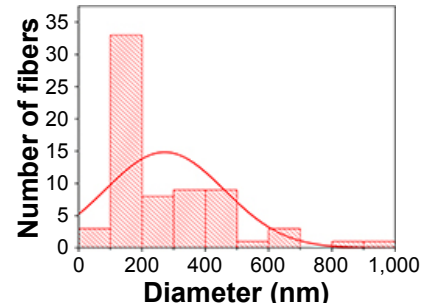

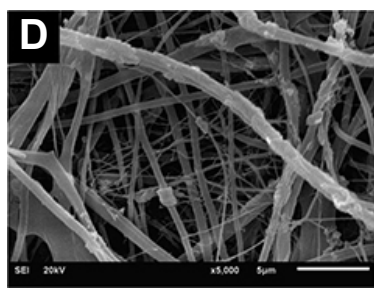

H

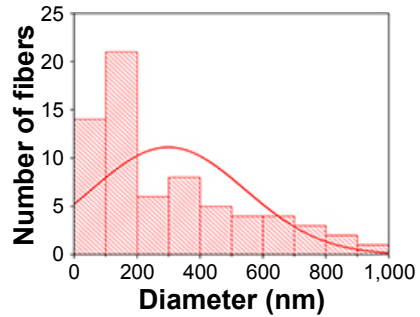

Figure I Scanning electron micrographs of the four electrospun fibrous membranes: (A) CS, (B) A0, (C) AI, and (D) A2; (E-H) the corresponding diameter distribution diagrams.

Abbreviation: CS, chitosan.

Without crosslinking, the prepared electrospun CS membrane lost integrity in aqueous solution. Therefore, the use of an appropriate crosslinking agent is essential to improve the stability and mechanical property of CS membranes. In this study, we chose vanillin as the crosslinking agent due to its lower cytotoxicity than that of the common crosslinking agents, for example, glutaraldehyde and formaldehyde..$^{38,39}$ It has been shown that vanillin-crosslinked CS microspheres
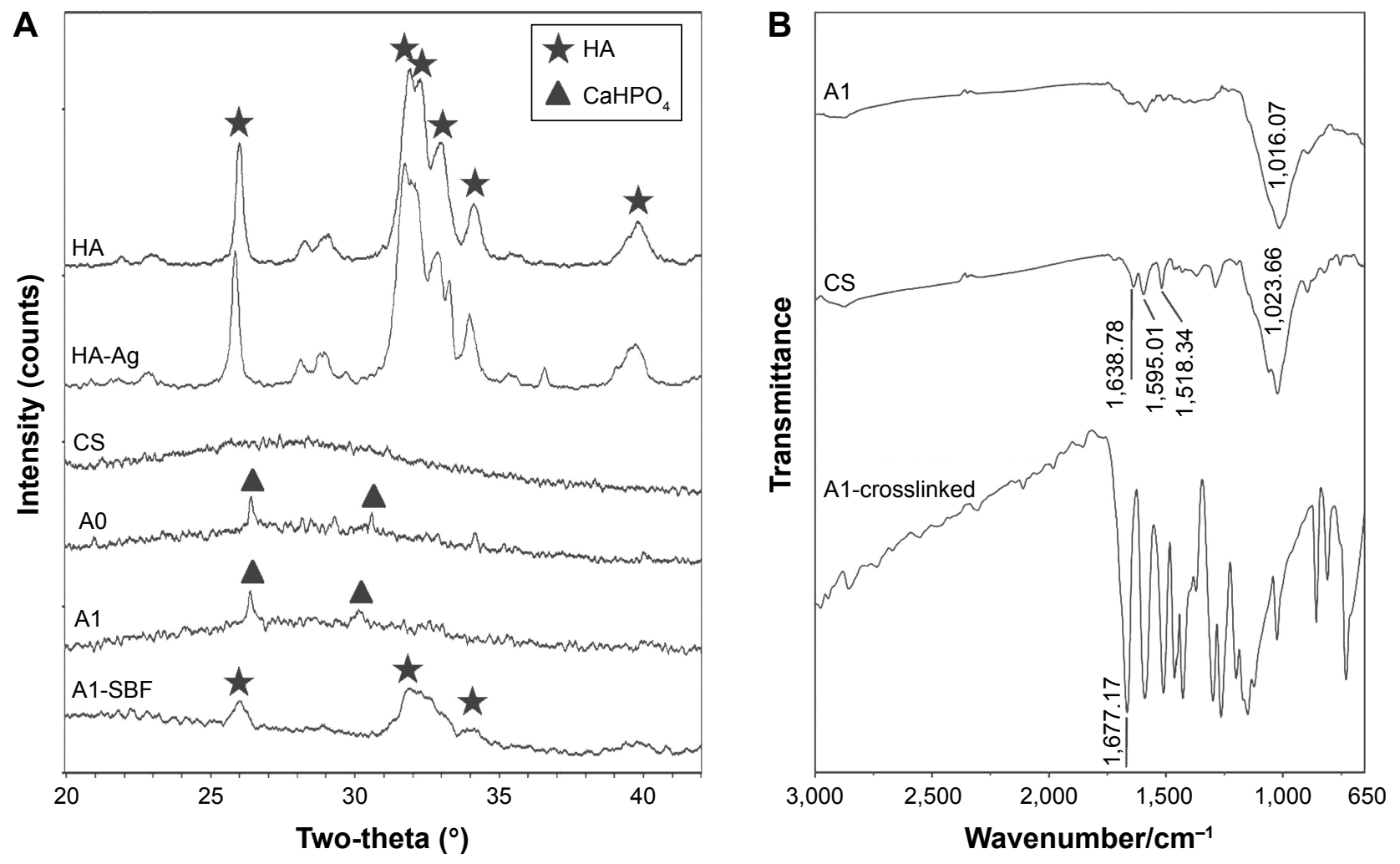

Figure 2 (A) XRD patterns of calcium phosphate particles (HA and HA-Ag), electrospun membranes (CS, A0, and AI), AI immersed in SBF for 2 weeks (AI-SBF), and (B) FTIR spectra of $\mathrm{AI}, \mathrm{CS}$, and $\mathrm{AI}$ crosslinked by vanillin (AI-crosslinked).

Abbreviations: CS, chitosan; FTIR, Fourier transform infrared; HA, hydroxyapatite; HA-Ag, silver loaded hydroxyapatite; SBF, simulated body fluid; XRD, X-ray diffraction. 
displayed a better cytocompatibility and much weaker inflammatory reaction than glutaraldehyde-crosslinked CS microspheres. ${ }^{40}$ Vanillin reacts with CS through the Schiff base reaction between the aldehyde groups of vanillin and the amine groups of CS. The characteristic absorption peak of $\mathrm{C}=\mathrm{N}$ is seen at $1,677 \mathrm{~cm}^{-1}$ in Figure 2B, which indicates that the Schiff base reaction occurred.

\section{The distribution of $\mathrm{CaP}$ and $\mathrm{Ag}^{+}$}

It is widely accepted that the distribution of nanoparticles in fibers directly influences the performance of membrane. EDS mapping was used to characterize the distribution of $\mathrm{CaP}$ and
$\mathrm{Ag}^{+}$in the $\mathrm{Ag}-\mathrm{CaP} / \mathrm{CS}$ composite membrane. As shown in Figure 3, the EDS spectrogram further proved the presence of $\mathrm{CaP}$ and $\mathrm{Ag}^{+}$in fibers. The homogeneous distribution of $\mathrm{Ca}, \mathrm{P}$, and $\mathrm{Ag}$ elements in EDS mapping indicated that the silver ion-loaded $\mathrm{CaP}$ nanoparticles were homogeneously distributed in the fibers.

\section{The silver ion loading and release XPS analysis}

XPS was applied to further confirm the chemical composition and the valence states of the prepared membranes. The XPS spectra of HA-Ag, A1, and A1 crosslinked by vanillin
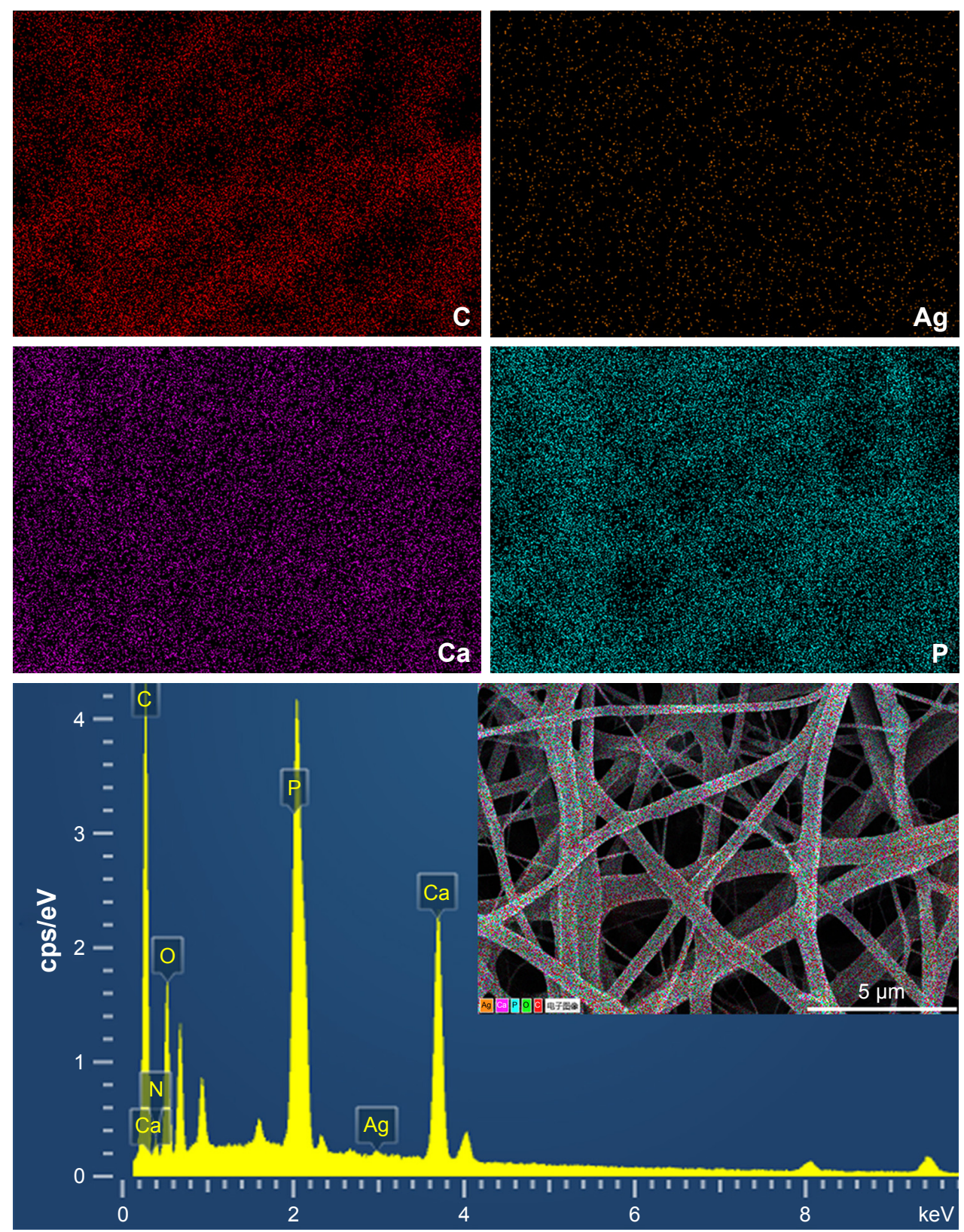

Figure 3 The distribution of $\mathrm{CaP}$ and silver ions in the $\mathrm{A} 2$ membrane. 
nanofiber membranes are shown in Figure 4A-C. The presence of the characteristic peak of $\mathrm{Ag} 3 \mathrm{~d}$ indicated that silver ions were successfully incorporated into the electrospun fibrous membranes. The binding energy of $\mathrm{Ca}$ and $\mathrm{P}$ did not change obviously in the three survey spectra. The characteristic peak of sodium was observed in A1 and A1-crosslinked membranes, which can be explained by the incorporation of sodium in the process of stabilization of the membranes by sodium hydroxide solution. XPS is also a powerful technique to explore the oxidation state of the transition metal compounds with localized valence orbital due to the different energies of the photoelectrons. From the high resolution XPS spectra of $\mathrm{Ag} 3 \mathrm{~d}$ (inserted images), the binding energy fits well to a single spin-orbit pair of $\mathrm{Ag} 3 \mathrm{~d}_{5 / 2}$ at $367.6 \mathrm{eV}$ and $\mathrm{Ag} 3 \mathrm{~d}_{3 / 2}$ at $373.6 \mathrm{eV}$, respectively, which is attributed to $\mathrm{Ag}^{+}{ }^{12,41}$ The spectra of $\mathrm{Ag} 3 \mathrm{~d}$ for A1-crosslinked nanofibers illustrated that the valence state of silver ions was stable univalent silver during the electrospinning and

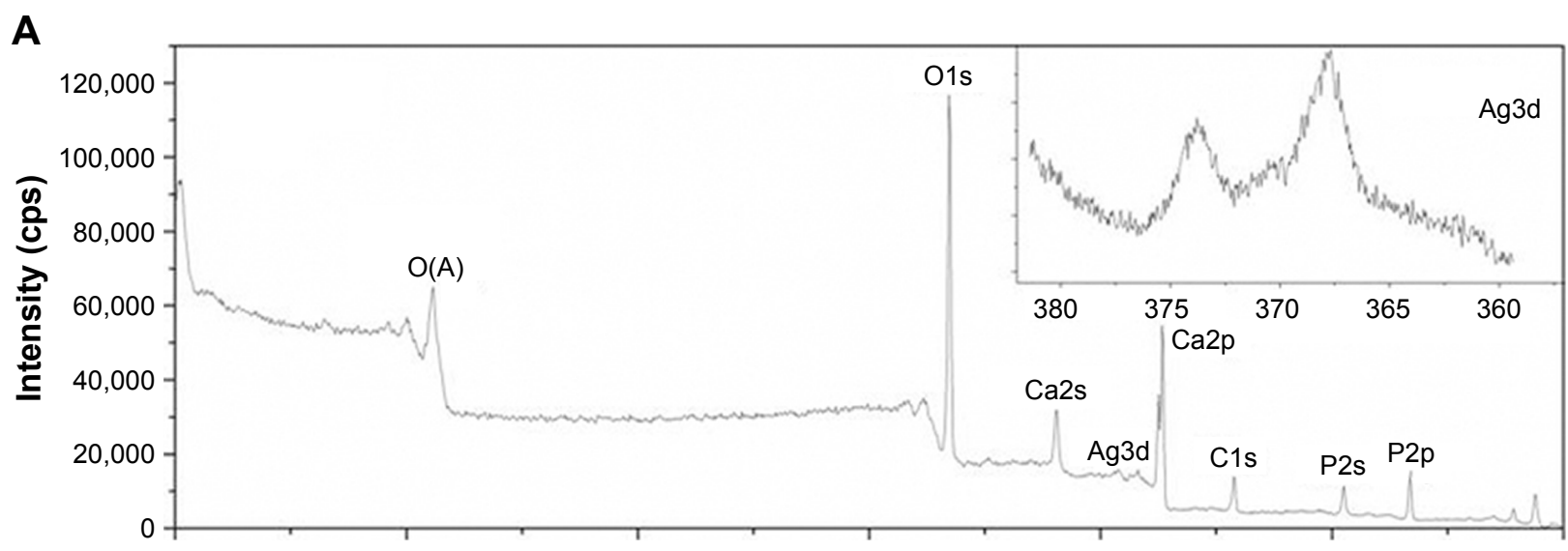

B

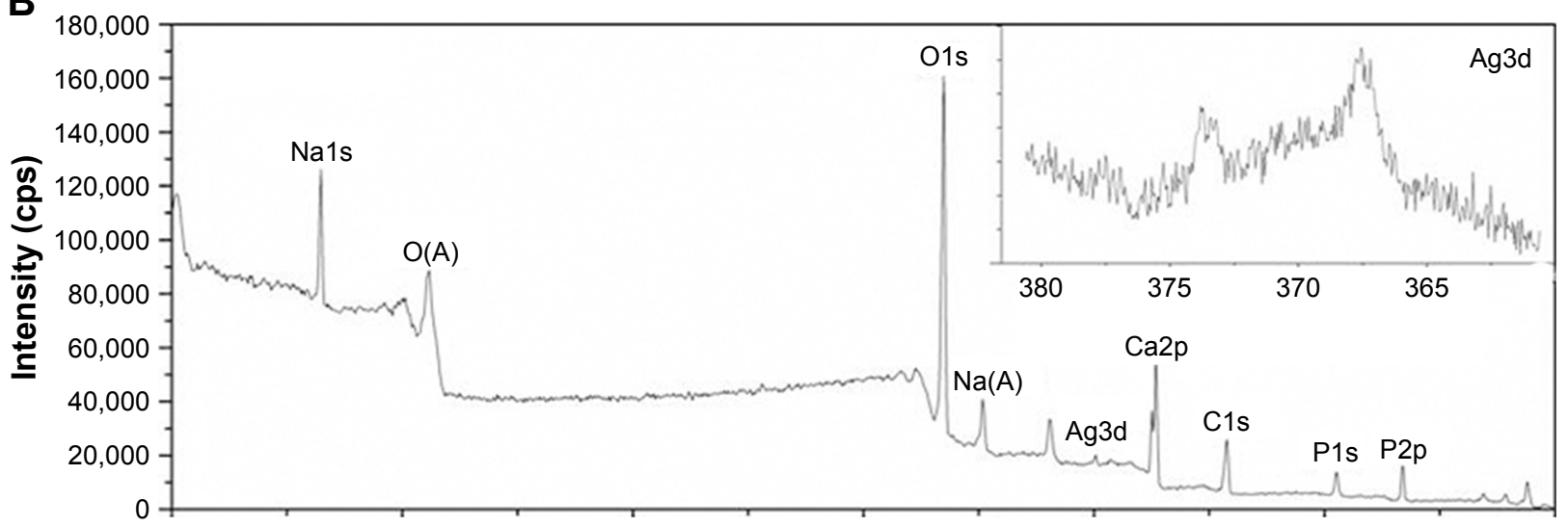

C

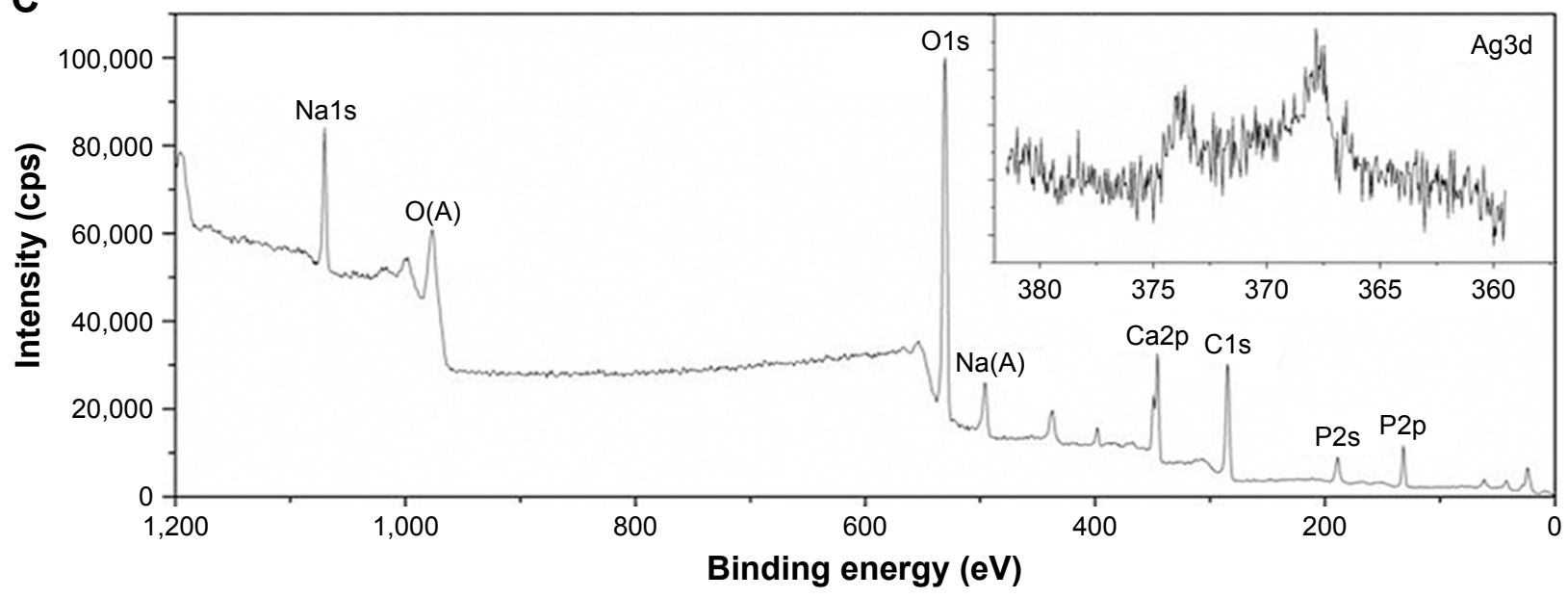

Figure 4 (Continued) 


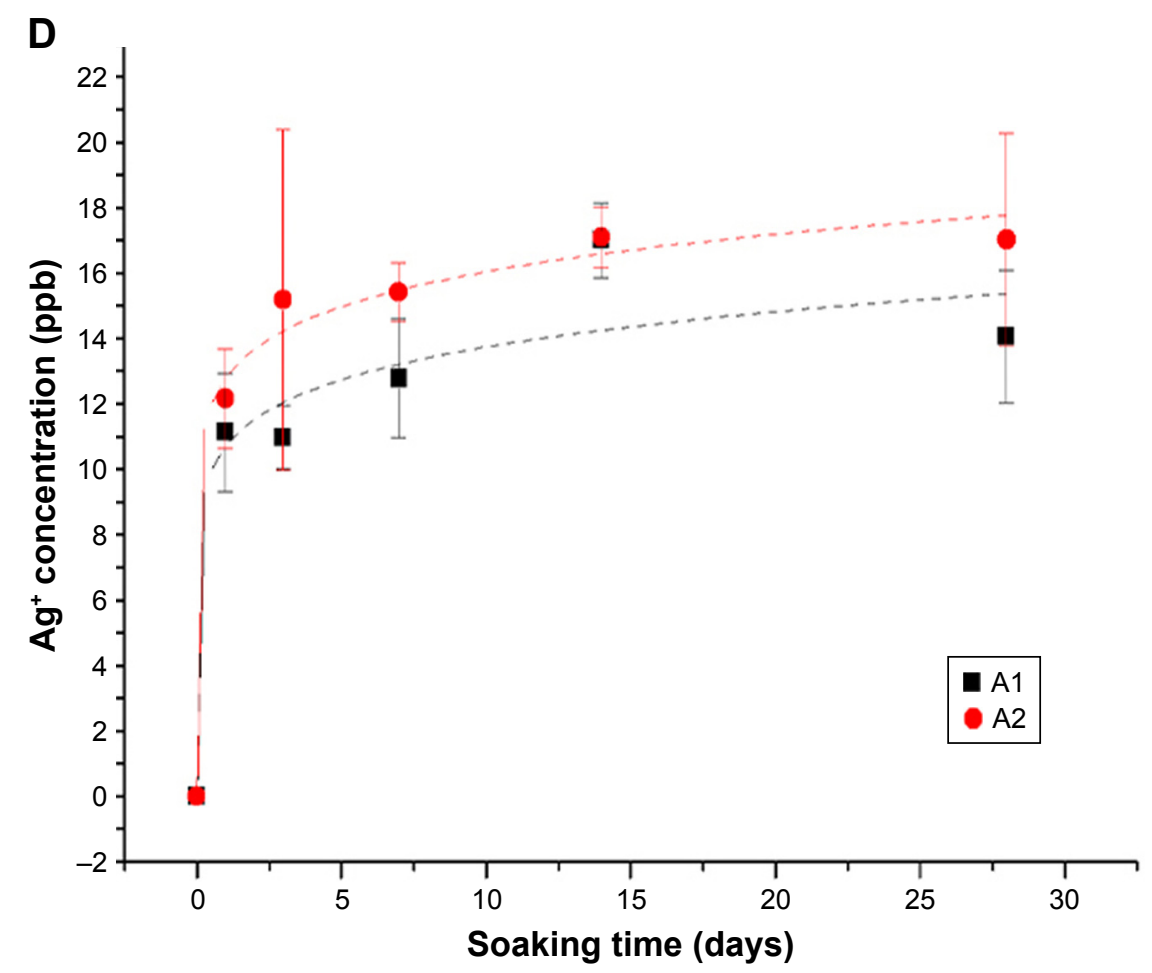

Figure 4 XPS spectra (A) silver-loaded hydroxyapatite, (B) AI, (C) Al crosslinked by vanillin. (D) Concentration of silver ions released from different silver-loaded electrospun fibrous membranes in deionized, distilled water.

crosslinking process, which provides the necessary evidence of the antibacterial action of silver ions in the membrane.

\section{The release of silver ions in vitro}

The release behaviors of $\mathrm{Ag}^{+}$from the $\mathrm{Ag}-\mathrm{CaP} / \mathrm{CS}$ nanofiber membranes was evaluated by in vitro release evaluation (Figure 4D). As the results indicated, apparently, both A1 and $\mathrm{A} 2$ exhibited an evident initial burst release within the first day and the amount of the $\mathrm{Ag}^{+}$released from nanofiber membranes increased slowly with augmentation of soaking time, after 1 day. Although there was no statistical difference between $\mathrm{A} 1$ and $\mathrm{A} 2$, the amount of $\mathrm{Ag}^{+}$released from $\mathrm{A} 2$ was slightly higher than that released from A1 after 1 day. $\mathrm{Ag}^{+}$physically absorbed on $\mathrm{A} 0$ membrane was used to assess the $\mathrm{Ag}^{+}$release behaviors as the control. Robust burst release of $\mathrm{Ag}^{+}$physically absorbed on $\mathrm{A} 0$ after 1 day immersion was observed and release amount reached $76.8 \%$ of the total absorbed $\mathrm{Ag}^{+}$. Therefore, we did not test the release of $\mathrm{Ag}^{+}$ physically absorbed on A0 for a longer period. Although the burst release of $\mathrm{Ag}^{+}$from $\mathrm{A} 1$ and $\mathrm{A} 2$ was also observed, the amount of $\mathrm{Ag}^{+}$released from $\mathrm{A} 1$ and $\mathrm{A} 2$ after 1 day immersion was not $>30 \%$ of the total $\mathrm{Ag}^{+}$in the membranes. Thus, $\mathrm{A} 1$ and $\mathrm{A} 2$ showed a relatively slow release for $\mathrm{Ag}^{+}$in comparison with $\mathrm{Ag}^{+}$physically absorbed on the fabricated membrane group. The release of $\mathrm{Ag}^{+}$could be explained by a complex mechanism that includes diffusion, swelling, and corrosion. ${ }^{42}$ The release of $\mathrm{Ag}^{+}$should be first separated from the calcium phosphate surface and then be released from the CS nanofiber matrix. Therefore, a considerable part of $\mathrm{Ag}^{+}$was released within 24 hours, which might achieve a strong antibacterial effect during the early stage after surgery. Another mechanism is that a portion of $\mathrm{Ag}^{+}$diffused into the solution along with the degradation of $\mathrm{CS}$ and $\mathrm{CaP}$.

\section{Immersion in SBF}

The bone-linking ability of the different composite nanofiber membranes was assessed by examining the apatitic mineralization ability on the surface of membranes by incubation of the membranes in SBF. Figure 5 shows the SEM image of the surface morphology of the membranes after incubation in SBF for up to 2 weeks. The surface morphology of pure CS did not show any noticeable change after either 1- or 2-week immersion (Figure 5A and D). In contrast, both $\mathrm{A} 0$ and $\mathrm{A} 1$ were covered with some spherical minerals and the amount of mineral deposition increased with the immersion time (Figure 5B vs 5C, 5E vs 5F). However, the crystal structure of the mineral deposition could not be identified by the XRD patterns (Figure 2A, A1-SBF). The deposition 

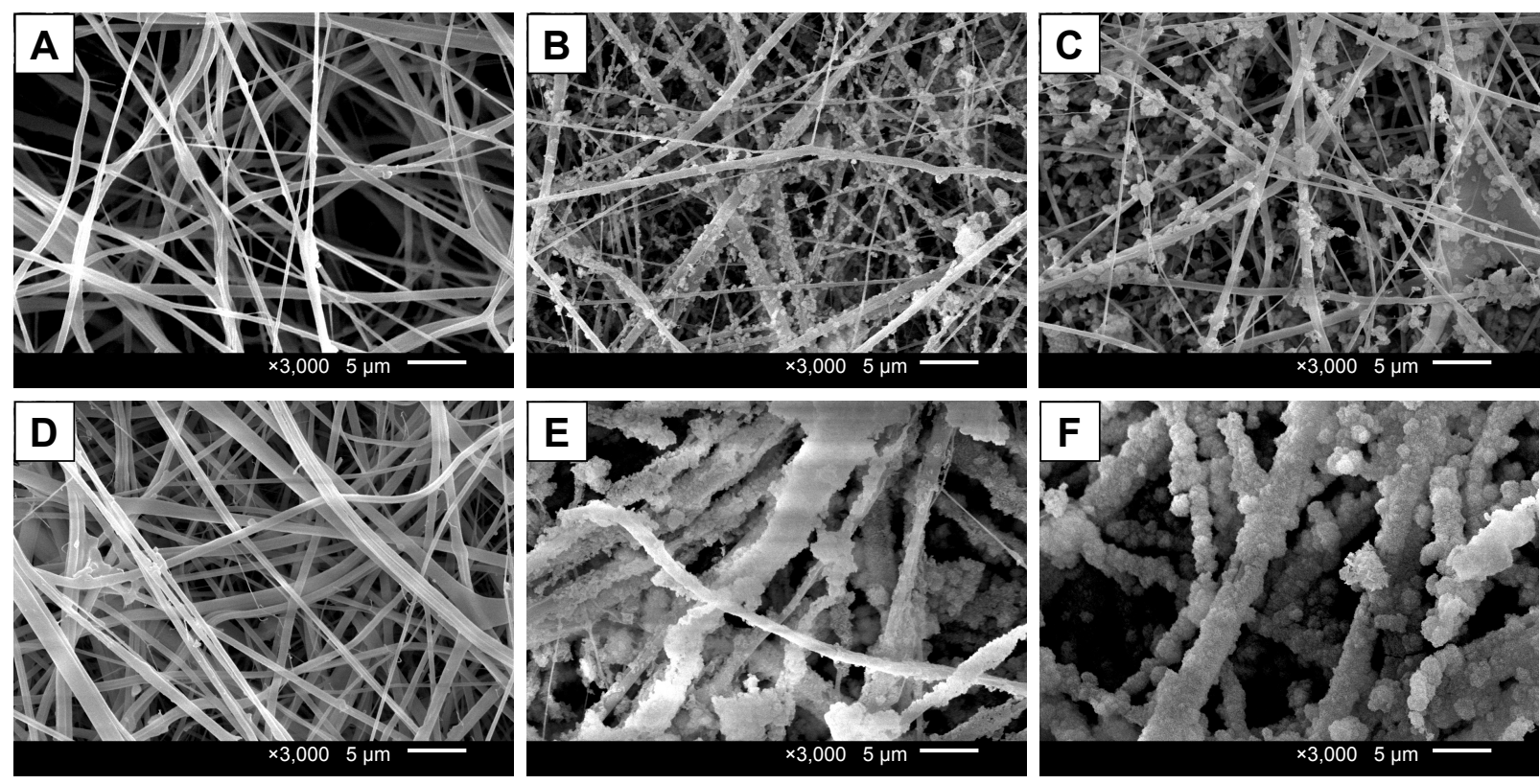

Figure 5 SEM photos of the electrospun membranes after immersion in SBF: (A) CS, (B) A0, and (C) AI for I week; (D) CS, (E) A0, and (F) AI for 2 weeks. Abbreviations: CS, chitosan; SBF, simulated body fluid; SEM, scanning electron micrograph.

of apatite can be explained by the nucleation and growth mechanism. Briefly, the increased local concentration of ions contributed to the formation of nucleation points; thereafter, the $\mathrm{CaP}$ nuclei formed and gradually grew into crystals. As a result, the hemispheric apatite formed and accumulated on the surface of fibers over time. The incorporation of $\mathrm{CaP}$ into the fibers provided nucleation points for the deposition of apatite. ${ }^{43}$ The results suggested that the addition of $\mathrm{CaP}$ significantly increased the mineralization ability of the membranes, which is beneficial for bone formation.

\section{Antimicrobial analysis \\ Anti-adhesion of $P$. gingivalis}

$P$. gingivalis, the gram-negative and the main pathogenic bacteria of peri-implantitis or periodontitis, was used to investigate the antimicrobial activity of various membranes. After immersion of the membranes in the bacterial suspension for 24 hours, the adhesion and growth of $P$. gingivalis on the fibrous membranes were observed by SEM, and the results are shown in Figure 6. Notably, the serried bacteria attached to the fibers to form a bead necklace structure of pure $\mathrm{CS}$ and $\mathrm{CaP} / \mathrm{CS}$ (A0). Moreover, a lot of diminutive bacteria were present, which indicated that the $P$. gingivalis can rapidly proliferate and grow on the surface of membranes. On the contrary, only a few bacteria could be found on the membranes with $\mathrm{Ag}^{+}(\mathrm{A} 1$ and $\mathrm{A} 2)$, and the bacteria on $\mathrm{A} 2$ membrane seemed to be slightly less than on $\mathrm{A} 1$. The results demonstrated that the prepared membranes with $\mathrm{Ag}^{+}$had strong antibacterial properties as we expected, which would greatly reduce the risk of postoperative infection.

\section{Anti-adhesion of S. mutans}

S. mutans, a common oral bacterium, was employed to evaluate the anti-adhesion effect of the prepared membranes. After incubation of the membranes with $S$. mutans suspension for 24 hours, SEM observation indicated that large numbers of bacteria adhered on the surface of the $\mathrm{CS}$ and $\mathrm{CaP} / \mathrm{CS}(\mathrm{A} 0)$, whereas few of them could be found on the $\mathrm{Ag}-\mathrm{CaP} / \mathrm{CS}$ membranes (A1 and A2; Figure 7A-D). In other words, membranes with $\mathrm{Ag}^{+}$restrained the adhesion and reproduction of the bacteria on the membrane surface. Low bacterial adhesion would prevent the formation of biofilm, and consequently reduce the risk of a biomaterial-centered infection. ${ }^{44}$ It is reported that the mechanism of the antibacterial activity of the silver ion is by attaching to the cell wall of bacteria and disturbing the permeability and intermembrane exchange. In addition, the antimicrobial action of silver ions is closely related to their interaction with phosphorous- and sulfurcontaining biomolecules, including DNA and proteins, by weakening DNA replication and inactivating proteins. ${ }^{45}$

\section{Evaluation of antimicrobial activity by DCT}

Furthermore, a modified DCT approach was used to assess the antimicrobial activity of the four fibrous membranes. 

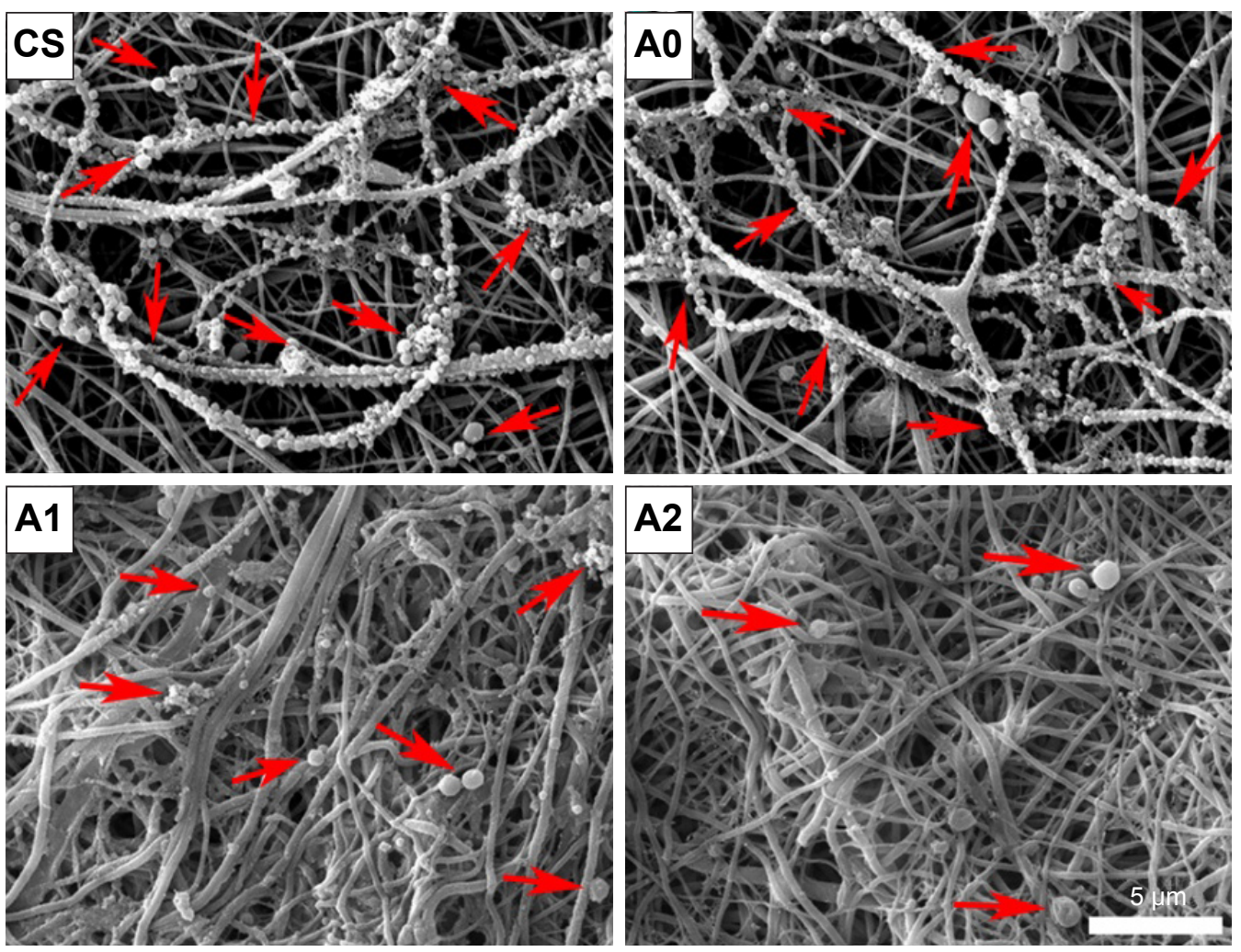

Figure 6 SEM image of bacterial growth on various membranes after 24 hours of co-culture with Porphyromonas gingivalis (as indicated by the red arrow). Abbreviations: CS, chitosan; SEM, scanning electron micrograph.

In the presence of the membranes, that is, the test in group A wells, only the $\mathrm{Ag}-\mathrm{CaP} / \mathrm{CS}$ membranes (A1 and A2) inhibited the proliferation of bacteria within 24 hours, whereas bacteria cultured with $\mathrm{A} 0$ and pure CS proliferated at the same rate as the control group (Figure 7E). The situation in vivo was a dynamic system with the exchange of body fluid, resulting in the loss of antibiotic constituents around the implanted materials. Thus, we utilized the group B wells to assess the growth of residual bacteria after just 1 hour of direct contact with the membrane. Unlike the results obtained from group A wells, only A2 exhibited complete inhibition of bacterial proliferation for up to 24 hours (Figure 7F). Bacteria in contact with A1 began to proliferate after 4 hours of incubation. The DCT indicates that the antibacterial property of $\mathrm{Ag}-\mathrm{CaP} / \mathrm{CS}$ composite membranes was associated with the amount of the incorporated silver. We learned that there are, indeed, related studies demonstrating that CS itself has a certain antibacterial effect. ${ }^{46,47}$ In contrast, research has also shown that CS does not have an antimicrobial effect. ${ }^{26,48}$ There is a controversial point about the antibacterial properties of CS. We think that whether or not CS exhibits antibacterial properties may be related to the source of its extraction as well as the species of bacteria. In our present study, both gram-positive (S. mutans) and gram-negative ( $P$. gingivalis) bacteria were used to assess the antibacterial properties and the results indicated that CS did not exhibit antibacterial effect.

\section{Cell morphology and proliferation of BMSCs}

BMSCs were used to evaluate the attachment, spread and growth of cells on the membranes. As shown in Figure 8, the morphology of BMSCs on the surface of different membranes after incubation for 4 and 7 days was observed by SEM. All of the membranes facilitated good attachment and growth of cells except for pure CS membrane. This is in accordance with the previous studies which showed that unmodified CS membranes did not perform sufficiently to mediate cell adhesion. ${ }^{49,50}$ After 4 days of incubation, cells on the membranes were flat and polygonal and the parapodia of BMSCs extended into the fibrous structure of the membranes. At day 7, the cells on the composite membranes were almost confluent. As the fibrous framework of biodegradable polymer membrane, the micro-nanostructure can act as an ECM for cell attachment and adhesion. The difference in the cell growth between the CS and composite membranes is likely due to the addition of $\mathrm{CaP}$, which may increase the 

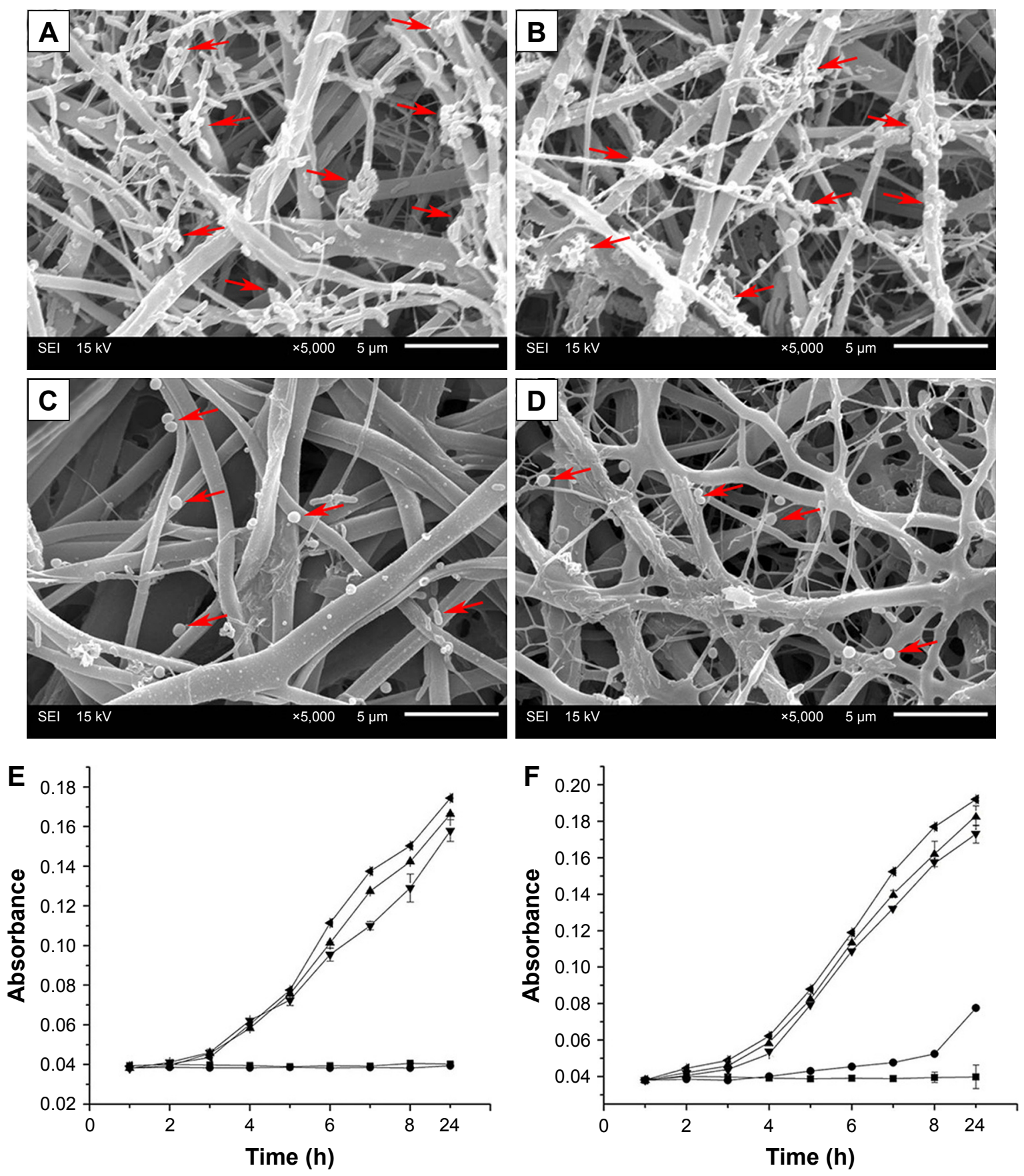

$$
\rightarrow-\mathrm{A} 2 \rightarrow \mathrm{A} 1 \rightarrow \mathrm{A} 0 \rightarrow \mathrm{CS} \longleftarrow \text { Control }
$$

Figure 7 SEM images of bacterial adhesion on (A) CS, (B) A0, and (C) Al and (D) A2 after 24 hours of incubation with Streptococcus mutans (as indicated by the red arrow). DCT results of the four membranes in (E) group $A$ and $(\mathbf{F})$ group $B$ after 24 hours of incubation.

Abbreviations: CS, chitosan; DCT, direct contact test; SEM, scanning electron micrograph.

surface roughness and protein adsorption to promote cell adhesion. ${ }^{4,51}$ In addition, $\mathrm{Ca}$ and $\mathrm{P}$ are necessary elements for human metabolism, which can transduce the chemical signal into the cell, thereby modulating a series of cell behaviors. ${ }^{52}$
The proliferation of BMSCs on the nanofiber membranes was investigated by MTT assays. Figure 9 shows the cell viability after culturing for $1,4,7$, and 11 days. With increasing culture time, obviously, the number of cells on the nanofiber membranes significantly increased. The proliferation 

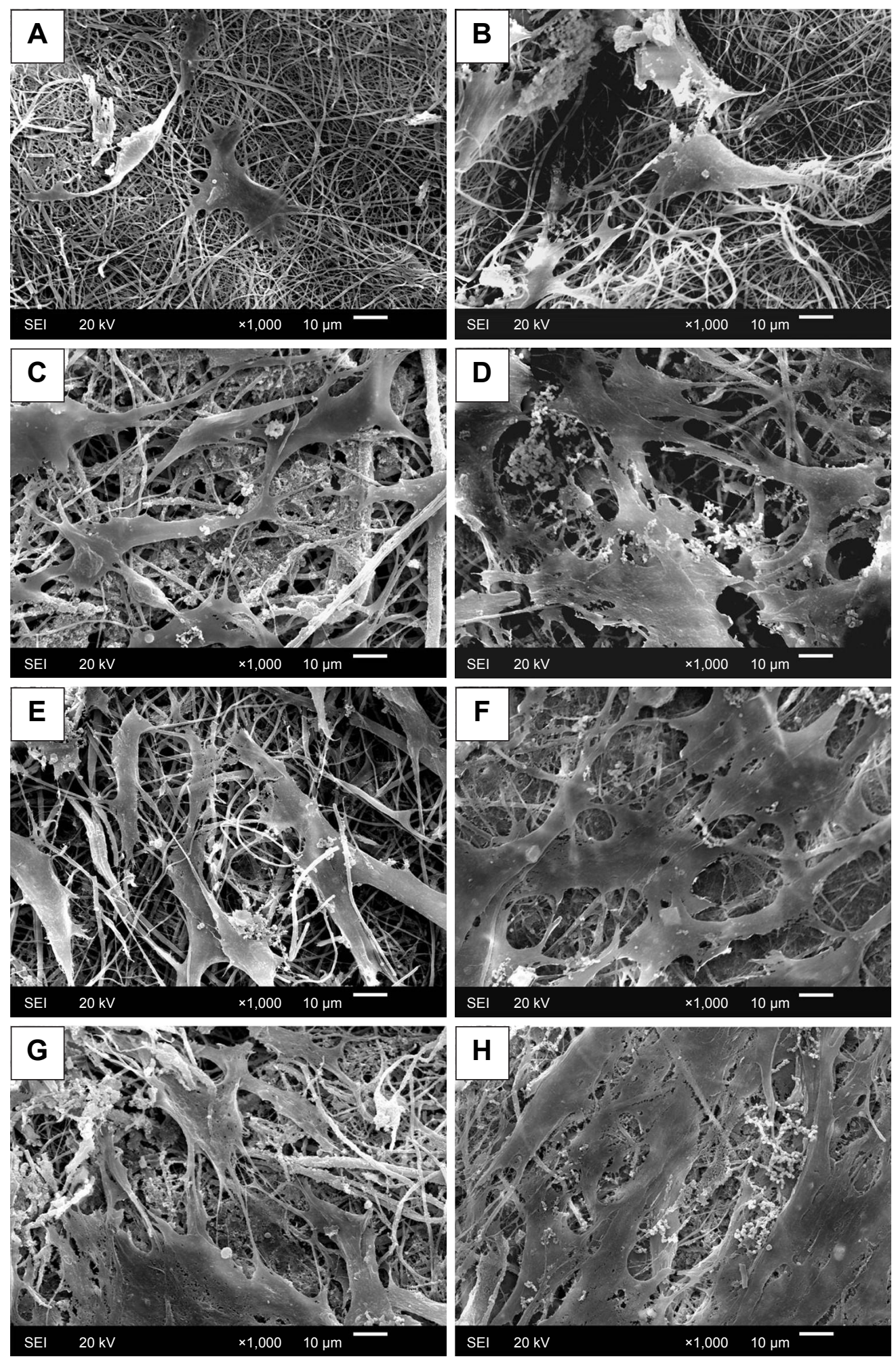

Figure 8 SEM images of BMSCs on the surface of $(\mathbf{A}, \mathbf{B}) \mathrm{CS},(\mathbf{C}, \mathbf{D}) \mathrm{A} 0$, and $(\mathbf{E}, \mathbf{F}) \mathrm{AI}$ and $(\mathbf{G}, \mathbf{H}) \mathrm{A} 2$ after $(\mathbf{A}, \mathbf{C}, \mathbf{E}, \mathbf{G}) 4$ days and $(\mathbf{B}, \mathbf{D}, \mathbf{F}, \mathbf{H}) 7$ days of incubation. Abbreviations: BMSCs, bone marrow stromal cells; CS, chitosan; SEM, scanning electron micrograph.

of BMSCs on A0, A1, and A2 was distinctly higher than on pure CS membrane, which is consistent with the SEM results. The incorporation of $\mathrm{CaP}$ facilitated cell adhesion on the surface of membranes, thereby significantly promoting the proliferation of BMSCs. ${ }^{52}$ However, the cell viability of A0 was higher than those of A1 and A2, suggesting that the addition of silver ions inhibited cell proliferation to some extent, but the silver-loaded membranes were still 


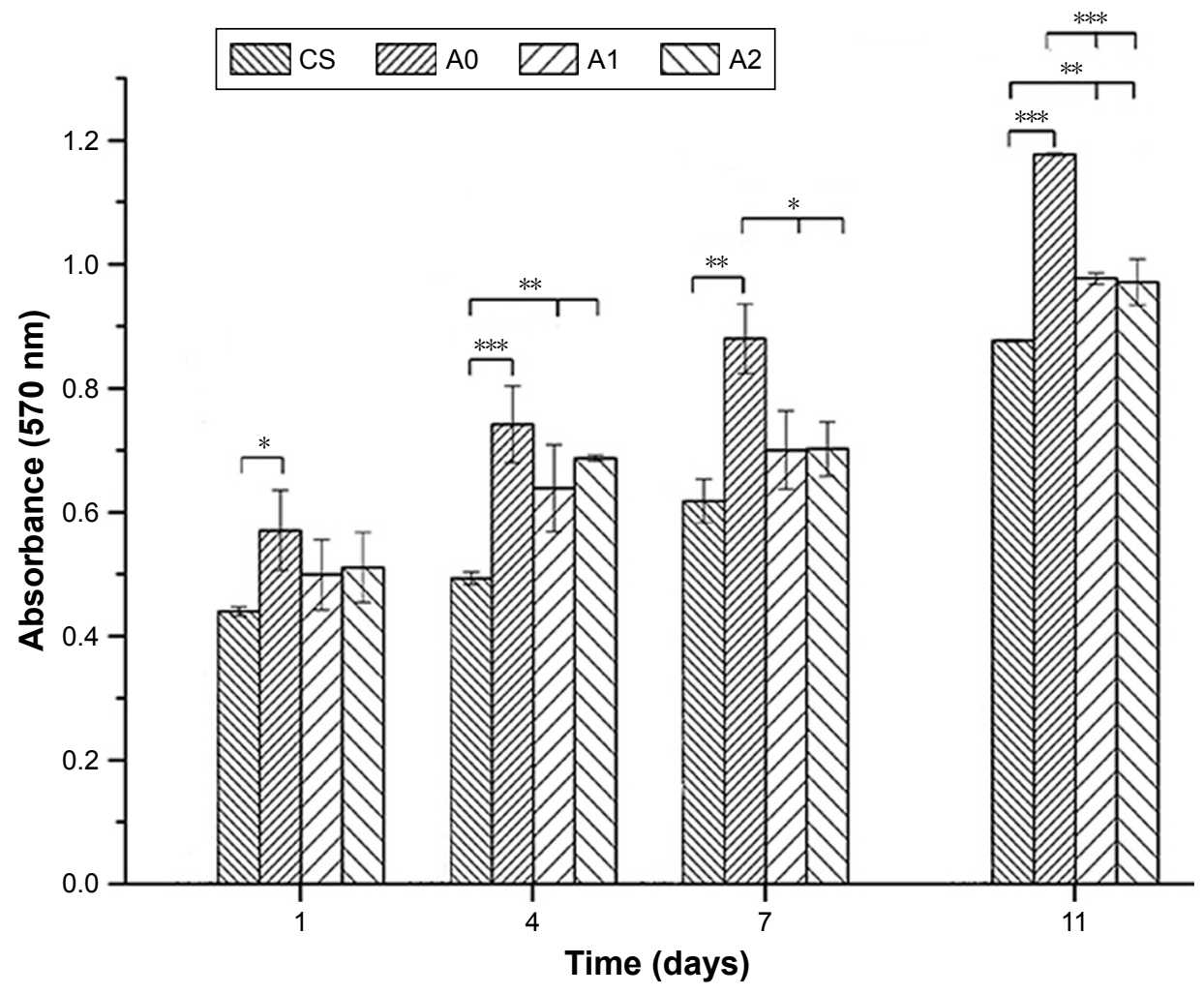

Figure 9 MTT assay of BMSCs cultured on the membranes.

Notes: Error bars represent SD from the mean $(n=3)$. *** $P<0.001$; $* * P<0.01 ; * P<0.05$.

Abbreviations: BMSCs, bone marrow stromal cells; CS, chitosan.

superior to pure CS membrane for BMSCs proliferation. The Ag-CaP/CS composite membranes with an optimal concentration of $\mathrm{Ag}^{+}$could have simultaneously good cytocompatibility and antibacterial properties. Bacteria are prokaryotes and human cells are eukaryotic cells with integrated nuclei..$^{53}$ Therefore, eukaryotic cells are larger than prokaryotic cells and a higher concentration of $\mathrm{Ag}^{+}$ is required to cause cytotoxicity on human cells than on bacterial cells. This difference provides a "therapeutic window" for the membranes to achieve biocompatibility and antibacterial properties at the same time. ${ }^{4}$ This result also indicates that although a higher content of silver ions in the membrane will achieve stronger antibacterial activity, it will lead to corresponding cytotoxicity. ${ }^{54}$ Therefore, an optimal concentration of silver in biomaterial is of great importance. The fabricated membrane of A2 achieved good cytocompatibility and strong antibacterial properties simultaneously, so we did not further increase the concentration of silver ions in the membrane in this study.

\section{Conclusion}

In this study, $\mathrm{Ag}-\mathrm{CaP} / \mathrm{CS}$ bioactive composite fibrous membranes with antibacterial properties were successfully developed by electrospinning method and subsequently crosslinked with vanillin as the potential candidate for GBR application. The physicochemical properties evaluated suggested that the fabricated fibrous membranes mimicked the ECM structure and the addition of $\mathrm{CaP}$ significantly increased the apatite mineralization ability of the membranes. Most importantly, the silver ions were successfully incorporated into the fibers, and thereby endowed the membranes with antibacterial function. The incorporation of $0.144 \%$ content of silver ions into the nanofibers (A2) endows the fibrous membranes with strong antibacterial properties without induction of adverse cytotoxicity. Hence, the fabricated Ag-CaP/CS fibrous membranes showing a combination of excellent biocompatibility and strong antimicrobial properties have great potential to be used for GBR.

\section{Acknowledgments}

The authors acknowledge the support of the National Key Research and Development Program of China (2016YFA0201703/2016YFA0201700) and NFSC fund (31670965).

\section{Disclosure}

The authors report no conflicts of interest in this work. 


\section{References}

1. Benic GI, Hämmerle CH. Horizontal bone augmentation by means of guided bone regeneration. Periodontology. 2014;66(1):13-40.

2. Bottino MC, Thomas V, Schmidt G, et al. Recent advances in the development of GTR/GBR membranes for periodontal regeneration - a materials perspective. Dent Mater. 2012;28(7):703-721.

3. Jang TS, Lee EJ, Jo JH, Jh J, et al. Fibrous membrane of nano-hybrid poly-L-lactic acid/silica xerogel for guided bone regeneration. J Biomed Mater Res B Appl Biomater. 2012;100(2):321-330.

4. Li J, Zuo Y, Man Y, et al. Fabrication and biocompatibility of an antimicrobial composite membrane with an asymmetric porous structure. J Biomater Sci Polym Ed. 2012;23(1-4):81-96.

5. Song X, Ling F, Ma L, Yang C, Chen X. Electrospun hydroxyapatite grafted poly(L-lactide)/poly(lactic-co-glycolic acid) nanofibers for guided bone regeneration membrane. Compos Sci Technol. 2013;79:8-14.

6. Zhang H, Wang J, Ma H, Hr M, et al. Bilayered PLGA/wool keratin composite membranes support periodontal regeneration in beagle dogs. ACS Biomater Sci Eng. 2016;2(12):2162-2175.

7. Zhang H-L, Wang J, Yu N, Liu J-S. Electrospun PLGA/multi-walled carbon nanotubes/wool keratin composite membranes: morphological, mechanical, and thermal properties, and their bioactivities in vitro. J Polym Res. 2014;21(1):329.

8. Gentile P, Chiono V, Tonda-Turo C, Ferreira AM, Ciardelli G. Polymeric membranes for guided bone regeneration. Biotechnol J. 2011;6(10): 1187-1197.

9. Mcallister BS, Haghighat K. Bone augmentation techniques. J Periodontol. 2007;78(3):377-396.

10. von Arx T, Buser D. Horizontal ridge augmentation using autogenous block grafts and the guided bone regeneration technique with collagen membranes: a clinical study with 42 patients. Clin Oral Implants Res. 2006;17(4):359-366.

11. Li J, Man Y, Zuo Y, et al. In vitro and in vivo evaluation of a nHA/ PA66 composite membrane for guided bone regeneration. J Biomater Sci Polym Ed. 2011;22(1-3):263-275.

12. Tang Y, Subramaniam VP, Lau TH, et al. In situ formation of largescale $\mathrm{Ag} / \mathrm{AgCl}$ nanoparticles on layered titanate honeycomb by gas phase reaction for visible light degradation of phenol solution. Appl Catal B. 2011;106(3-4):577-585.

13. Peng H, Yin Z, Liu H, et al. Electrospun biomimetic scaffold of hydroxyapatite/chitosan supports enhanced osteogenic differentiation of mMSCs. Nanotechnology. 2012;23(48):485102.

14. Shen K, Hu Q, Chen L, Shen J. Preparation of chitosan bicomponent nanofibers filled with hydroxyapatite nanoparticles via electrospinning. J Appl Polym Sci. 2010;115(5):2683-2690.

15. Ren K, Wang Y, Sun T, Yue W, Zhang H. Electrospun PCL/gelatin composite nanofiber structures for effective guided bone regeneration membranes. Mater Sci Eng C Mater Biol Appl. 2017;78:324-332.

16. Su H, Liu KY, Karydis A, et al. In vitro and in vivo evaluations of a novel post-electrospinning treatment to improve the fibrous structure of chitosan membranes for guided bone regeneration. Biomed Mater. 2016;12(1):015003.

17. Zeugolis DI, Khew ST, Yew ES, et al. Electro-spinning of pure collagen nano-fibres - just an expensive way to make gelatin? Biomaterials. 2008;29(15):2293-2305.

18. Celebi H, Gurbuz M, Koparal S, Dogan A. Development of antibacterial electrospun chitosan/poly(vinyl alcohol) nanofibers containing silver ion-incorporated HAP nanoparticles. Compos Interfaces. 2013; 20(9):799-812.

19. Hassiba AJ, El Zowalaty ME, Nasrallah GK, et al. Review of recent research on biomedical applications of electrospun polymer nanofibers for improved wound healing. Nanomedicine. 2016;11(6):715-737.

20. van Hong Thien D, Hsiao SW, Ho MH, Li CH, Shih JL, Mh H, Ch L. Electrospun chitosan/hydroxyapatite nanofibers for bone tissue engineering. J Mater Sci. 2013;48(4):1640-1645.
21. Zhang Y, Venugopal JR, El-Turki A, Ramakrishna S, Su B, Lim CT. Electrospun biomimetic nanocomposite nanofibers of hydroxyapatite/ chitosan for bone tissue engineering. Biomaterials. 2008;29(32): 4314-4322.

22. Zhao W, Liu W, Li J, Lin X, Wang Y. Preparation of animal polysaccharides nanofibers by electrospinning and their potential biomedical applications. J Biomed Mater Res A. 2015;103(2):807-818.

23. Zhou Y, Yang H, Liu X, Mao J, Gu S, Xu W, Sj G, W1 X. Electrospinning of carboxyethyl chitosan/poly(vinyl alcohol)/silk fibroin nanoparticles for wound dressings. Int J Biol Macromol. 2013;53:88-92.

24. Bedolla-Cázares F, Hernández-Marcelo PE, Gómez-Hurtado MA, et al. Silver nanoparticles from AgNO3-affinin complex synthesized by an ecofriendly route: chitosan-based electrospun composite production. Clean Technol Environ Policy. 2017;19(3):897-906.

25. Fouda MM, El-Aassar MR, Al-Deyab SS. Antimicrobial activity of carboxymethyl chitosan/polyethylene oxide nanofibers embedded silver nanoparticles. Carbohydr Polym. 2013;92(2):1012-1017.

26. Song J, Remmers SJ, Shao J, et al. Antibacterial effects of electrospun chitosan/poly(ethylene oxide) nanofibrous membranes loaded with chlorhexidine and silver. Nanomedicine. 2016;12(5):1357-1364.

27. López-Esparza J, Espinosa-Cristóbal LF, Donohue-Cornejo A, Reyes-López SY. Antimicrobial activity of silver nanoparticles in polycaprolactone nanofibers against gram-positive and gram-negative bacteria. Ind Eng Chem Res. 2016;55(49):12532-12538.

28. Scoccianti G, Frenos F, Beltrami G, Campanacci DA, Capanna R. Levels of silver ions in body fluids and clinical results in silver-coated megaprostheses after tumour, trauma or failed arthroplasty. Injury. 2016; 47(Suppl 4):S11-S16.

29. Zhuang X, Cheng B, Kang W, Xu X, Xl X. Electrospun chitosan/ gelatin nanofibers containing silver nanoparticles. Carbohydr Polym. 2010;82(2):524-527.

30. Mp L, Jd L, Quan ZX, Ys O, Jiang DM, Yb L. In vitro evaluation of antibacterial activity and cytotoxicity of novel nanocomposite material for bone filling. Mater Res Innov. 2013;15(1):24-28.

31. Wu X, Li J, Wang L, Huang D, Zuo Y, Li Y, Jd L, Yb L. The release properties of silver ions from Ag-nHA/TiO2/PA66 antimicrobial composite scaffolds. Biomed Mater. 2010;5(4):044105.

32. Gao C, Feng P, Peng S, Shuai C. Carbon nanotube, graphene and boron nitride nanotube reinforced bioactive ceramics for bone repair. Acta Biomater. 2017;61:1-20.

33. Frohbergh ME, Katsman A, Botta GP, et al. Electrospun hydroxyapatitecontaining chitosan nanofibers crosslinked with genipin for bone tissue engineering. Biomaterials. 2012;33(36):9167-9178.

34. Kokubo $\mathrm{T}$, Takadama $\mathrm{H}$. How useful is $\mathrm{SBF}$ in predicting in vivo bone bioactivity? Biomaterials. 2006;27(15):2907-2915.

35. Anumula L, Kumar S, Kumar VS, et al. An assessment of antibacterial activity of four endodontic sealers on Enterococcus faecalis by a direct contact test: an in vitro study. ISRN Dent. 2012;2012:989781-989785.

36. Wang J, Zuo Y, Zhao M, et al. Physicochemical and biological properties of a novel injectable polyurethane system for root canal filling. Int J Nanomedicine. 2015;10:697-709.

37. Shellis RP, Barbour ME, Jones SB, Addy M. Effects of $\mathrm{pH}$ and acid concentration on erosive dissolution of enamel, dentine, and compressed hydroxyapatite. Eur J Oral Sci. 2010;118(5):475-482.

38. Buslovich A, Horev B, Rodov V, Gedanken A, Poverenov E. One-step surface grafting of organic nanoparticles: in situ deposition of antimicrobial agents vanillin and chitosan on polyethylene packaging films. J Mater Chem B. 2017;5(14):2655-2661.

39. Yang H-J, Lee J-H, Lee K-Y, Song KB. Antimicrobial effect of an Undaria pinnatifida composite film containing vanillin against Escherichia coli and its application in the packaging of smoked chicken breast. Int J Food Sci Technol. 2017;52(2):398-403.

40. Zou Q, Li J, Li Y, Jd L, Yb L. Preparation and characterization of vanillin-crosslinked chitosan therapeutic bioactive microcarriers. Int J Biol Macromol. 2015;79(4):736-747. 
41. Zhao Y, Zhou Y, Wu X, Wang L, Xu L, Wei S. A facile method for electrospinning of Ag nanoparticles/poly (vinyl alcohol)/carboxymethylchitosan nanofibers. Appl Surf Sci. 2012;258(22):8867-8873.

42. Zheng F, Wang S, Wen S, Shen M, Zhu M, Shi X. Characterization and antibacterial activity of amoxicillin-loaded electrospun nanohydroxyapatite/poly(lactic-co-glycolic acid) composite nanofibers. Biomaterials. 2013;34(4):1402-1412.

43. Mokabber T, Lu LQ, van Rijn P, Vakis AI, Pei YT. Crystal growth mechanism of calcium phosphate coatings on titanium by electrochemical deposition. Surf Coat Technol. 2018;334:526-535.

44. Yang WJ, Yang CS, Huang CJ, Chen KS, Lin SF, Bostrycin LSF. Bostrycin, a novel coupling agent for protein immobilization and prevention of biomaterial-centered infection produced by Nigrospora sp. No. 407. Enzyme Microb Technol. 2012;50(6-7):287-292.

45. Zhou Y, Kong Y, Kundu S, Cirillo JD, Liang H. Antibacterial activities of gold and silver nanoparticles against Escherichia coli and bacillus Calmette-Guérin. J Nanobiotechnology. 2012;10(1):19.

46. Dumont M, Villet R, Guirand M, et al. Processing and antibacterial properties of chitosan-coated alginate fibers. Carbohydr Polym. 2018; 190:31-42.

47. Huang C-Y, Kuo C-H, Wu C-H, Ku M-W, Chen P-W, Ch W, Mw K. Extraction of crude chitosans from squid (Illex argentinus) pen by a compressional puffing-pretreatment process and evaluation of their antibacterial activity. Food Chem. 2018;254:217-223.
48. Stroescu M, Stoica-Guzun A, Isopencu G, et al. Chitosan-vanillin composites with antimicrobial properties. Food Hydrocoll. 2015;48: $62-71$.

49. López-Pérez PM, da Silva RMP, Serra C, Pashkuleva I, Reis RL. Surface phosphorylation of chitosan significantly improves osteoblast cell viability, attachment and proliferation. J Mater Chem. 2010;20(3): 483-491.

50. Silva SS, Luna SM, Gomes ME, et al. Plasma surface modification of chitosan membranes: characterization and preliminary cell response studies. Macromol Biosci. 2008;8(6):568-576.

51. Nagasaki T, Nagata F, Sakurai M, Kato K. Effects of pore distribution of hydroxyapatite particles on their protein adsorption behavior. Journal of Asian Ceramic Societies. 2017;5(2):88-93.

52. Gao C, Peng S, Feng P, Shuai C. Bone biomaterials and interactions with stem cells. Bone Res. 2017;5:17059.

53. Reidy B, Haase A, Luch A, Dawson K, Lynch I. Mechanisms of silver nanoparticle release, transformation and toxicity: a critical review of current knowledge and recommendations for future studies and applications. Materials. 2013;6(6):2295-2350.

54. Dds L, Gullon B, Cardelle-Cobas A, et al. Chitosan-based silver nanoparticles: a study of the antibacterial, antileishmanial and cytotoxic effects. J Bioact Compat Poly. 2016;32(4):397-410.
International Journal of Nanomedicine

\section{Publish your work in this journal}

The International Journal of Nanomedicine is an international, peerreviewed journal focusing on the application of nanotechnology in diagnostics, therapeutics, and drug delivery systems throughout the biomedical field. This journal is indexed on PubMed Central,

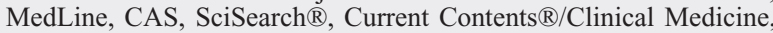

\section{Dovepress}

Journal Citation Reports/Science Edition, EMBase, Scopus and the Elsevier Bibliographic databases. The manuscript management system is completely online and includes a very quick and fair peer-review system, which is all easy to use. Visit http://www.dovepress.com/ testimonials.php to read real quotes from published authors. 